\title{
Health Issues confronting Muslims on Hajj
}

\section{Murtaza Ali Gowa, Syed Ali Ammar, Ahmed Ali, Syed Muhammad Kashif Kazmi, Rana Farrukh, Ali Abbas Mohsin Ali \&}

\section{Syed Muhammad Mustahsan}

Sultan Qaboos Hospital, Oman

National Institute of Cardiovascular Disorders, Karachi

Doctors Clinic, Dubai

Ziauddin Medical University Hospital, Karachi

Jinnah Postgraduate Medical Centre, Karachi

Corresponding Author: msutu198@gmail.com

\begin{abstract}
Objective: To determine the prevalence of health issues among hajj pilgrims and the factors associated with them. Method: An observational study conducted during hajj (Year 2011) using a questionnaire which was filled by pilgrims on their visit to the health clinics conducted by the Imamia Medics International. Results: During the period, pilgrims presented complaints related to the respiratory system $52.5 \%(\mathrm{n}=394)$ followed by musculoskeletal system $29.6 \%(\mathrm{n}=222)$, gastrointestinal system $15.5 \%(\mathrm{n}=116)$, skin problems $5.9 \%(\mathrm{n}=44)$, central nervous system $3.1 \%(\mathrm{n}=23)$, cardiovascular system $2.9 \%(\mathrm{n}=22)$, reproductive system $2.7 \%(\mathrm{n}=20)$, urinary tract problems $2.3 \%(\mathrm{n}=17)$ were dealt with.

Out of $750,17.9 \%(n=134)$ were diabetic and $26.4 \%(n=198)$ were hypertensive. Amongst the total, 24.8\% ( $n=186)$ were vaccinated against hepatitis while $35.7 \%(n=268)$ were vaccinated against pneumonia. An astonishingly high percentage of the pilgrims had no prior immunization to both hepatitis and pneumonia. Conclusion: This data tries to emphasize awareness regarding the importance of vaccination and the potential problems which are faced by diabetic, hypertensive and older population which can help to improve the health condition of hajj pilgrims and can lessen the burden faced by concerned authorities.
\end{abstract}

\section{Introduction}

Hajj, the pilgrimage to Makkah and holy places is one of the 5 pillars of Islam that every financially and physically able Muslims must perform once in their lifetime (Arabi; 2006). It is a special season where more than 2,000,000 Muslims from more than 140 countries gather in the holy shrine (Al-Mashaer) to perform this important ritual of Islam (Al-Ghamdi; 2003). The rituals of Hajj are performed from the 8th-13th of the last month of the Islamic lunar calendar in the city of Makkah and the adjacent Al-Mashaer area (which includes Mina and Arafat) in the Kingdom of Saudi Arabia (KSA), (Khan; 2006).

The annual spectacle of millions of pilgrims flooding Makkah has captured the imagination of generations of readers (Hurgronje; 1931). The hajj is a physical and knowledge intensive activity (Harmain; 2004). Pilgrims show increased belief in peace, and in equality and harmony among adherents of different religions. The evidence suggests that these changes are likely due to exposure to and interaction with Hajjis from around the world, rather than to a changed social role of pilgrims upon return (Clingingsmith; 2008). The mass migration during the Hajj is unparalleled in scale, and pilgrims face numerous health hazards. The extreme congestion of people and vehicles during this time amplifies health risks, such as those from infectious diseases that vary each year (Ahmed; 2006). For the individual pilgrim this is a deeply spiritual journey that represents the culmination of months if not years of preparation (Gatrad; 2006).

A sound knowledge about the health problems faced by the pilgrims is therefore important for effective management of health services. Our work is based on knowing the prevalence of different health problems and the factors related to these problems. The results can help the concerned authorities to have a more focused and effective approach towards the health care of pilgrims.

\section{Method}

An observational study was conducted on hajj (Year 2011) by the IMI Hajj Medical Mission. Hajjis came to the out-patient clinics run throughout the visit by IMI team. The number of daily clinics and the number of patients have significantly increased during the stay.

A standardized questionnaire was designed to collect the information which contains demographic questions and clinical questions. The questionnaire was filled by the hajjis attending the out-patient clinics. The data was collected and then dependent and independent variables were made.

The dependent variable was: the clinical complaints of hajjis and their vaccination status and co-morbids. The independent variable was: the demographics questions (age, gender, prior hajj, hajj scheme, marital status, residential city, distance between haram and hotel and any physical disability).

Statistical Package for Social Sciences (SPSS-20) was used for statistical analyses.

\section{Result}

A total of 750 patients took part in the research. Among them most of the presented complaints observed were related to respiratory system $52.5 \%(\mathrm{n}=394)$ followed by the musculoskeletal system $29.6 \%(\mathrm{n}=222)$, gastrointestinal system $15.5 \%(\mathrm{n}=116)$, skin problems $5.9 \%(\mathrm{n}=44)$, central nervous system $3.1 \%(\mathrm{n}=23)$, cardiovascular system $2.9 \%(\mathrm{n}=22)$, reproductive system $2.7 \%(\mathrm{n}=20)$, urinary tract problems $2.3 \%(\mathrm{n}=17)$ and some other non-specific problems as shown in table 1 . We also found $17.9 \%(\mathrm{n}=134)$ known to have a case of diabetes mellitus and $26.4 \%(\mathrm{n}=198)$ were of hypertension and out of 750 hajjis, only $24.8 \%(n=186)$ were vaccinated from hepatitis and $35.7 \%(n=268)$ from pneumonia as shown in figure 1. A major amount of the hajjis were unvaccinated.

The most common age group people visiting the clinics was between 51 to 60 years $(28.1 \%)$ followed by 41 to 50 years (25.9\%) and 31 to 40 years (19.7\%). The majority of the Hajjis were married $(95.6 \%)$. Some interesting facts we found were that $68.1 \%(n=511)$ of our patients belonged to urban area, a common category of hajj scheme was private $62 \%(\mathrm{n}=465)$, most of the patients had their hotels within $1 \mathrm{~km}$ radius of haram (53.9\%) and $28 \%(\mathrm{n}=3.7)$ of them were physical disabled.

Figure 1: Vaccinated Peoples before arriving for Hajj

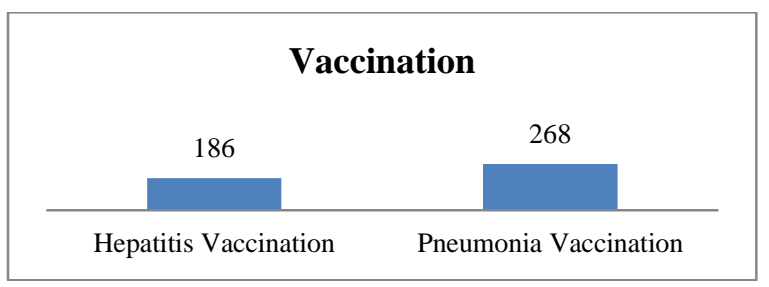




\begin{tabular}{|c|c|c|c|c|}
\hline \multirow[b]{2}{*}{$\begin{array}{l}\text { Table 1: Common Presenting Complaints at } \\
\text { the time of Hajj }\end{array}$} & \multicolumn{2}{|c|}{ Frequency } & \multicolumn{2}{|c|}{ Cumulative Percent } \\
\hline & Yes & No & Yes & No \\
\hline Cardiovascular Related Complaints & 22 & 728 & $2.9 \%$ & $97.1 \%$ \\
\hline Respiratory System Related Complaints & 394 & 356 & $52.5 \%$ & $47.5 \%$ \\
\hline Musculo-Skeletal System Related Complaints & 222 & 528 & $29.6 \%$ & $70.4 \%$ \\
\hline Gastric Complaints & 116 & 634 & $15.5 \%$ & $84.5 \%$ \\
\hline Urinary Complaints & 17 & 733 & $2.3 \%$ & $97.7 \%$ \\
\hline Reproductive System Related Complaints & 20 & 730 & $2.7 \%$ & $97.3 \%$ \\
\hline Central Nervous System Related Complaints & 23 & 727 & $3.1 \%$ & $96.9 \%$ \\
\hline Skin Problems & 44 & 706 & $5.9 \%$ & $94.1 \%$ \\
\hline Other Complaints & 40 & 710 & $5.3 \%$ & $94.7 \%$ \\
\hline
\end{tabular}

\section{Discussion}

Each year, approximately 2 million Muslims travel from all over the world to participate in hajj (El bashir; 2004). Because the hajj is one of Islam's five fundamentals which all Muslims of sufficient means are obliged to observe, its significance too often has been assumed to be the same for Muslims everywhere (Donnan; 1989). Hajj, the center of Islamic World in Mecca is not possible without long preparations, efforts, often sufferings and endurance of hardship; it requires great effort and exertion (Nasr; 1999). Our study focused on the health issues faced by the hajj pilgrims. The impact of the current pandemic on Hajj pilgrims is unpredictable, preparedness is clearly indicated. Participation, cooperation, and commitment by home countries will be critical. Because many pilgrims originate from resource poor countries (Ebrahim; 2009).

According to our data, our patients were mostly above 50 yrs so the likelihood of falling ill, developing more serious medical complications and death is understandably high in such elderly pilgrims (Madani; 2007). There was a male pre-dominance $53.5 \%$ and most of the pilgrims were from urban areas $68.1 \%$. The majority of the complaints were related to the respiratory system $52.5 \%$ because Acute respiratory tract infections are very common during the Hajj, particularly so when the pilgrimage falls in the winter season. The close contact among pilgrims during periods of intense congestion, their shared sleeping accommodations (mainly in tents) and the dense air pollution all combine to increase the risk of airborne respiratory disease transmission (Memish; 2010). We also gathered many complaints of the musculoskeletal system $29.6 \%$ and skin $5.9 \%$, this was mainly due to the over-crowdedness and as mentioned earlier because of intense congestion and close contact. Old age, poor physical fitness, multiple diseases, neglect in continuous treatment of known chronic diseases and failure to seek early medical advice were the major factors responsible for morbidity and mortality (Yousuf; 1995).

A focused approach towards the problems can help manage these patients effectively and in a lesser time period. In our settings, we found a large population was unvaccinated from pneumonia and hepatitis. It shows the need of vaccination programs and awareness which can have a massive impact on the improvement of the health conditions of the pilgrims. It is hoped that this data will be of help to health care planners, administrators, and officials to provide optimal and cost effective health care services to pilgrims in Hajj.

\section{Conflict of Interest}

There is no conflict of interest among the authors.

\section{Acknowledgment}

Special thanks to the IMI for providing services and facilitating the hajj pilgrims and giving a good platform to conduct this research. We also thank Dr.Sibte Arif Naqvi, Syed Nabeel Ali Akbar, Dr.Waseem Akhtar, Dr.Mudassir, Dr.Aqeel Jafri, Dr.Altaf, Dr.Ali Asghar, Dr.Fatima, Dr.Sajida Ahmed and Dr.Abiha for their support.

\section{References}

- Arabi, Y. M., \& Alhamid, S. M. (2006). Emergency room to the intensive care unit in Hajj. The chain of life. Saudi medical journal, 27(7), 937-941.

- Al-Ghamdi, S. M., Akbar, H. O., Qari, Y. A., Fathaldin, O. A., \& Al-Rashed, R. S. (2003). Pattern of admission to hospitals during muslim pilgrimage (Hajj). Saudi medical journal, 24(10), 10731076.

- Khan, N. A., Ishag, A. M., Ahmad, M. S., El-Sayed, F. M., Bachal, Z. A., \& Abbas, T. G. (2006). Pattern of medical diseases and determinants of prognosis of hospitalization during 2005 Muslim pilgrimage Hajj in a tertiary care hospital. A prospective cohort study. Saudi medical journal, 27(9), 1373-1380.

- Hurgronje, C. S. (1931). Mekka in the Latter Part of the 19th Century. Leiden: EJ Brill.

- Harmain, H. M., Khatib, H. E., Saeed, N., \& Aljohar, B. (2004). Web Services-Based Hajj Information System. In Proceedings of the International Conference on Information and Computer Science (ICICS). Dhahran, Saudi Arabia.

- Clingingsmith, D., Khwaja, A. I., \& Kremer, M. (2008). Estimating the impact of the Hajj: religion and tolerance in Islam's global gathering.

- Ahmed, Q. A., Arabi, Y. M., \& Memish, Z. A. (2006). Health risks at the Hajj. The Lancet, 367(9515), 1008-1015.

- Gatrad, A. R., Shafi, S., Memish, Z. A., \& Sheikh, A. (2006). Hajj and the risk of influenza. BMJ: British Medical Journal, 333(7580), 1182.

- El Bashir, H., Haworth, E., Zambon, M., Shafi, S., Zuckerman, J., \& Booy, R. (2004). Influenza among UK pilgrims to Hajj, 2003. Emerging infectious diseases, 10(10), 1882

- Donnan, H. (1989). Symbol and Status: The Significance of the Hajj in Pakistan. The Muslim World, 79(3-4), 205-216.

- Nasr, S. H. (1999). The spiritual significance of Jihad. Al-SeratA Journal of Islamic Studies, 9(1).

- Ebrahim, S. H., Memish, Z. A., Uyeki, T. M., Khoja, T. A., Marano, N., \& McNabb, S. J. (2009). Pandemic H1N1 and the 2009 Hajj. Science, 326(5955), 938.

- Madani, T. (2007). Causes of admission to intensive care units in the Hajj period of the Islamic year 1424 (2004). Ann Saudi Med., 27(2).

- Memish, Z. A. "The Hajj: communicable and non-communicable health hazards and current guidance for pilgrims." Euro Surveill 15.39 (2010): 19671.

- Yousuf, M., Al-Saudi, D. A., Sheikh, R. A., \& Lone, M. S. (1995). Pattern of medical problems among Haj pilgrims admitted to King Abdul Aziz Hospital, Madinah Al-Munawarah. Annals of Saudi medicine, 15(6), 619-621.

- Madani, T. A., Ghabrah, T. M., Al-Hedaithy, M. A., Alhazmi, M. A., Alazraqi, T. A., Albarrak, A. M., \& Ishaq, A. H. (2006). Causes of hospitalization of pilgrims during the Hajj period of the Islamic year 1423 (2003). Annals of Saudi medicine, 26(5), 346 . 